\title{
A Retrospective Study of Bacteriology and Antibiotic Sensitivity Pattern of Post Operative Surgical Site Infections in Orthopedics
}

\author{
R. Rajani $^{1}$ and J. Veerabhadra ${ }^{2 *}$ (D) \\ ${ }^{1}$ Department of Microbiology, Raichur institute of Medical Sciences, Raichur - 584 102, Karnataka, India. \\ ${ }^{2}$ Department of Orthopedics, Karwar institute of Medical Sciences, Karwar - 581 301, Karnataka, India.
}

\begin{abstract}
Surgical Site infection (SSI) is one of the most common post-operative complications and causes significant post-operative morbidity and mortality. The global estimates of SSI have varied from $0.5 \%$ to $15 \%$, studies in India have consistently shown higher rates ranging from $23 \%$ to $38 \%{ }^{1}$. The aim of the study was to know the etiological bacterial agents causing SSI and their antimicrobial susceptibility pattern. This retrospective study included 69 patients who developed Post-operative wound infections (SSI) during the 1-year period from April 2019 to March 2020. An analysis of SSI occurrence, the organisms isolated and antibiotic sensitivity pattern results was made. In overall surgeries conducted during the study period in orthopedics department at our institute, 69 cases were clinically diagnosed of having SSIs, including 51 males and 18 females with the mean age of 39.2 years. Out of the total 69 samples, $6(8.69 \%)$ yielded no bacterial growth and among the rest 63 samples, Staphylococcus aureus $21(30.43 \%)$ was the most common organism isolated. The other organisms isolated were Klebsiella pneumonia 13 (18.84\%), Pseudomonas 11 (15.94\%), Escherichia coli 5 (7.24\%), Proteus species 3 (4.34\%) and Acinetobacter species 3 (4.34\%). Mixed isolates were obtained in 2 (11.9\%) specimens. Bacteriological and antibiotic susceptibility study is an important tool to treat infection timely and effectively in-turn minimizing untoward long term sequelae of surgical site infections
\end{abstract}

Keywords: Surgical site infections, Antibiotic sensitivity, orthopedics

*Correspondence: drjavali@yahoo.co.in; +91 9620506900

(Received: March 30, 2021; accepted: July 01, 2021)

Citation: Rajani R, Veerabhadra J. A Retrospective Study of Bacteriology and Antibiotic Sensitivity Pattern of Post Operative Surgical Site Infections in Orthopedics. J Pure Appl Microbiol. 2021;15(3):1379-1383. doi: 10.22207/JPAM.15.3.29

(C) The Author(s) 2021. Open Access. This article is distributed under the terms of the Creative Commons Attribution 4.0 International License which permits unrestricted use, sharing, distribution, and reproduction in any medium, provided you give appropriate credit to the original author(s) and the source, provide a link to the Creative Commons license, and indicate if changes were made. 


\section{INTRODUCTION}

Surgical Site infection (SSI) is one of the most common post-operative complications and causes significant post-operative morbidity and mortality. While the global estimates of SSI have varied from $0.5 \%$ to $15 \%$, studies in India have consistently shown higher rates ranging from $23 \%$ to $38 \%^{1}$. CDC clearly defined SSI as an infection that occurs after surgery in the part of the body where the surgery took place and classified the SSI into superficial, deep and organ specific ${ }^{2}$. Surgical site infections cause increased morbidity, mortality, extended hospital stays, and additional economic burden to the hospital resources ${ }^{3,4}$.

In view of this, all necessary measures need to be undertaken to prevent infection and if SSI occurs every step need to be implemented immediately to curb and treat the infection at the earliest possible time. Determination of the etiologic agent and its susceptible antibiotics becomes one of the important tools for controlling infection. Hence the present study aims to identify the causative organisms and antibiotic susceptibility pattern .

\section{MATERIALS AND METHODS}

This retrospective study included 69 patients who developed Post operative wound infections (SSI) during the 1-year period from April 2019 to March 2020. A total of 578 patients were operated during the study period.

\section{Inclusion criteria}

- clean elective surgeries of the fracture of limbs.

- Closed Injuries

- Exclusion criteria

- Emergency surgeries,

- open injuries of the limbs and

- spinal surgeries.

Patients basic demographic data and the analysis of SSI occurrence, the organisms isolated and antibiotic sensitivity pattern evaluated was collected.

\section{Laboratory Procedures}

Swabs were obtained from the post operative infected wounds. A smear was prepared and stained by Gram-staining method for presumptive diagnosis ${ }^{5}$. Swabs were inoculated on blood and Mac-Conkey agar plates were incubated at $37^{\circ} \mathrm{C}$ overnight for 24 hours. Antimicrobial susceptibility testing was done by Kirby-Bauer disc diffusion method ${ }^{6}$ and interpretation was done according to Clinical Laboratory Standards Institute (CLSI) guidelines ${ }^{7}$.

\section{RESULTS}

From April 2019 to March 2020, a total of 69 (11.9\%) patients diagnosed to have SSI out of 578 operated orthopedic patients at our hospital. The total number of Male patients 45 and female patients were 24 . The mean age of the patients was 43.6 years (range 18 to 65 years). Orthopedic Surgeries included surgeries on shoulder-5, humerus-3, elbow-4, forearm bones-6, Hip -21, femur-7, knee and patella -10 , leg bones- 8 and ankle-5.

Out of the total 69 samples, 6 (8.69\%) yielded no bacterial growth and among the rest 63 samples, Staphylococcus aureus 21 (30.43\%) was the most common organism isolated. The other organisms isolated were Klebsiella pneumonia 13 (18.84\%), Pseudomonas 11 (15.94\%), Escherichia coli 5 (7.24\%), Proteus species 3 (4.34\%) and Acinetobacter speices 3 (4.34\%). Mixed isolates were obtained in $2(2.89 \%)$ specimens. Table 1 shows the various bacterial isolates obtained from patients with SSIs.

Table 1. Total organisms isolated from SSI

\begin{tabular}{lc}
\hline Isolated Organisms & $\begin{array}{c}\text { Number } \\
\text { (Percentage) }\end{array}$ \\
\hline $\begin{array}{l}\text { Staphylococcus aureus } \\
\text { (Including Coagulase negative }\end{array}$ & $21(30.43 \%)$ \\
Staphylococcus) & \\
Klebsiella pneumonia & $13(18.84 \%)$ \\
Pseudomonas aeruginosa & $11(15.94 \%)$ \\
Escherichia coli & $5(7.24 \%)$ \\
Acinetobacter species & $3(4.34 \%)$ \\
Proteus Species & $3(4.34 \%)$ \\
Mixed growth & $2(2.89 \%)$ \\
1. Specimen-3 isolates & \\
(E.coli, Acinetobacter, & (Total -7 isolates) \\
Proteus species) & \\
klebsielka, Acinetobacter, & \\
Proteus species) & \\
No growth & \\
\hline
\end{tabular}


Table 2. Antibiotic sensitivity (resistance in percentage) pattern among isolates

\begin{tabular}{lcccccc}
\hline Antibiotics & \multicolumn{5}{c}{ Organisms resistant to the antibiotic (in Percentage) } \\
& $\begin{array}{l}\text { Staphylococcus } \\
\text { aureus }\end{array}$ & $\begin{array}{c}\text { Klebsiella } \\
\text { pneumonia }\end{array}$ & $\begin{array}{c}\text { Pseudomonas } \\
\text { aeruginosa }\end{array}$ & $\begin{array}{c}\text { Escherichia } \\
\text { coli }\end{array}$ & $\begin{array}{c}\text { Acinetobacter } \\
\text { species }\end{array}$ & $\begin{array}{c}\text { Proteus } \\
\text { species }\end{array}$ \\
\hline Pencillin & 100 & NoT & NoT & NoT & NoT & NoT \\
Amoxicillin & 90.2 & 100 & 100 & 85.3 & 86.82 & 100 \\
Amoxicillin- & 45.67 & 97.2 & 88.2 & 79.3 & 70.8 & 76.4 \\
clavulanate & & & & & & \\
Ciprofloxacin & 44.5 & 37.5 & 86.2 & 22.9 & 35.8 & 55 \\
Ofloxacin & 37.6 & 25 & 56.8 & 17.3 & 24.72 & 45.86 \\
Gentamycin & 21.4 & 18 & 78.4 & 36.4 & 45.65 & 52.12 \\
Amikacin & 18.9 & 0 & 41.2 & 13.2 & 34.58 & 32.8 \\
Cefotaxime & NoT* & 88 & 83.7 & NoT & NoT & 56.8 \\
Cefazolin & 18.2 & 82 & 72.6 & NoT & 29.22 & 48.42 \\
Cotrimoxazole & 49.3 & 53 & 79.3 & 44.9 & 83.1 & 52.64 \\
Linezolid & 0 & NoT & NoT & NoT & NoT & NoT \\
Meropenem & NoT & 0 & 16.2 & 11 & 0 & 0 \\
Imepenem & NoT & 0 & 2.3 & 0 & 0 & 0 \\
Piperacillin & NoT & 2 & 28.7 & 22.2 & 43.98 & 32.9 \\
Piperacillin- & NoT & 28.2 & 11.1 & 9.8 & 12.24 & 6.4 \\
tazobactam & & & & & & NoT \\
Clindamycin & 0 & NoT & NoT & NoT & NoT & NoT \\
Vancomycin & 0 & NoT & NoT & NoT & NoT & NoT \\
\hline & & & & & &
\end{tabular}

*NoT- Not Tested

Antimicrobial susceptibility testing was done for all 63 isolates and the results obtained shown in Table-2. Staphylococcal isolates were completely resistant to penicillin and high degree of resistance to amoxicillin, ciprofloxacin, ofloxacin and mildly resistant to gentamycin and amikacin, Co-Trimaxozole. All the strains were sensitive to Linezolid, clindamycin and vancomycin.

Gram negative isolates which predominantly includes Klebsiella pneumonia, Pseudomonas aeruginosa, Escherichia coli, Acinetobacter species, Proteus Species were uniformly resistant to regularly prescribed antibiotics like Amoxicillin, Ciprofloxacin, Ofloxacin, Gentamycin, Amikacin, Cefotaxime, Cefazolin, Cotrimoxazole in varying proportions. Most of these isolates were sensitive to Imepenem and Piperacillin-Tazobactum. (Table-2)

\section{DISCUSSION}

Surgical site infections cause increased morbidity, mortality, extended hospital stays, and additional economic burden to the hospital resources ${ }^{3,4}$. In addition, patients may have physical limitations and significant reduction in the quality of life ${ }^{8}$. Hence atmost precautions and necessary steps has to be taken to prevent SSI. In event of any SSI, early aggressive treatment with antibiotics becomes an important step. Bacteriological and antibiotic susceptibility study is an useful tool.

In our study, Males were the most affected compared to the females and common age group was 35-50 years with the mean age of 39.2 years. Similar findings were found in a study by Nichols et al., age group involved was 19-50 years ${ }^{9}$ and in another study by Koyagura B et al., The mean age of the cases with SSI was $34.12 \pm 8.01$ years and males were affected predominantly ${ }^{10}$. But in a study by Jun Yang et al., there was no statistically significant correlation between sex and the SSI rate ${ }^{11}$.

In our study, Staphylococcus aureus and gram negative (Klebsiella spp. and Pseudomonas 
spp.) bacteria were the predominant isolates obtained. Similar results were obtained in studies by Kumar S et al., and Maksimovic et al. ${ }^{12,13}$

Antimicrobial sensitivity testing of the isolates showed higher rates of multidrug resistant (MDR) strains of the organisms.S. aureus showed the high frequency of resistance towards beta-lactam antibiotics. Resistance to amoxiclav (90.2\%) was found to be high. Least resistance was observed to cefazolin, gentamicin, and amikacin. The results are comparable to a study conducted By B Amare et al. ${ }^{14}$ All the $S$. aureus isolates were sensitive to linezolid and vancomycin. Similar results were obtained from studies by vikrant negi et al. ${ }^{15}$ and Roel T et al. ${ }^{16}$

In our study, Klebsiella pneumonia was the predominate gram negative isolate followed by pseudomonas aeurogenosa which is in contrast to studies by Devi PV et al. ${ }^{17}$ and Benabdelsalem A et al. ${ }^{18}$ where pseudomonas was the predominate isolate. In this study, Klebsiella pneumonia showed high resistance to Amoxicillin/clavulanic acid (97.2\%), Cefotaxime (88\%), cefazolin (82\%), Ciprofloxacin $(37.5 \%)$ and less resistance was noted for Piperacillin- Tazobactam (28.2\%), Gentamicin (18\%) and was sensitive to Amikacin and imepenem which is consistent by a study by Himanshu Narula et al. ${ }^{19}$

Pseudomonas aeruginosa isolates in this study showed high resistance to Amoxicillin/ clavulanic acid (88.2\%), Cefotaxime $(83.7 \%)$ and Cefaclor (72.6.2\%) Ciprofloxacin (86.2\%).Moderate resistance was shown to Ofloxacin (56.8\%), Amikacin (41.2\%) and Piperacillin (28.7\%) and less resistance was noted for Piperacillin/Tazobactam (11.1\%), while imepenem (2.3\%) showed least resistance of all. Similar observation was reported by Das $R$ et al. ${ }^{20}$

Antibiogram of other Gram-negative isolates showed most organisms were resistant to amoxycillin-clavulanic acid and other antibiotics of cephalosporin group and cotrimoxazole. Moderate susceptibility was seen to ciprofloxacin, ofloxacin, and amikacin. All were susceptible to Imepenem. In our study, prophylactic antibiotic inj cefotaxime $1000 \mathrm{mg}$ intravenous was preferred and majority of the isolates obtained were resistant to the antibiotic.

In Our study, Staphylococcus aureus, were the major pathogens causing Surgical site infections. By analyzing the antimicrobial susceptibility data, we suggest that vancomycin and linezolid were the most effective agents against gram positive organisms and piperacillin/ tazobactum and imipenem were the most effective agents against most of gram negative bacteria. Based on antibiogram, use of the most sensitive antibiotics as earliest possible would help to control infection and avoid injudicious use of antibiotics which may lead to antibiotic resistance.

\section{CONCLUSION}

Bacteriological and antibiotic susceptibility study is an important tool to treat infection timely and effectively in-turn minimizing untoward long term sequelae of surgical site infections.

Limitations

The limitations of this study is that we did not study the risk factors, operative variables affecting the development of SSI. The other limitation in our study was that anaerobic bacterial and fungal cultures were not done.

\section{ACKNOWLEDGMENTS}

None.

\section{CONFLICT OF INTEREST}

The authors declare that there is no conflict of interest.

\section{AUTHORS' CONTRIBUTION}

Both authors have made a substantial, direct and intellectual contribution to the work, and approved it for publication.

\section{FUNDING}

None.

\section{DATA AVAILABILITY}

All datasets generated or analyzed during this study are included in the manuscript.

\section{ETHICS STATEMENT}

The study was approved by Institutional Ethics Comittee (IEC), KRIMS, Karwar, Karnataka, India. Klebsiella sps. and Pseudomonas aeruginosa 


\section{REFERENCES}

1. Kamat US, Fereirra AM, Kulkarni MS, Motghare DD. A prospective study of surgical site infections in a teaching hospital in Goa. Indian J Surg. 2008;70(3):120124. doi: 10.1007/s12262-008-0031-y

2. Kolasinski W. Surgical site infections - review of current knowledge, methods of prevention. Pol Przegl Chir. 2019;91(4):41-47.

3. Fry DE. The economic costs of surgical site infection. Surg Infect (Larchmt). 2002;3(suppl 1):S37-S43. doi: 10.1089/sur.2002.3.s1-37

4. Urban JA. Cost analysis of surgical site infections. Surg Infect (Larchmt). 2006;7(suppl 1):S19-S22. doi: 10.1089/sur.2006.7.s1-19

5. Koneman EW, Allen SD, Janda WM, Schreckenberger PC, Winn WC Jr, editors. Color Atlas and Textbook of Diagnostic Microbiology. $5^{\text {th }}$ Ed. Lipincott-Raven Publishers: Philadelhia: Pa. 1997.

6. Bauer AW, Kirby WM, Sherris JC, Turck M. Antibiotic susceptibility testing by a standard single disc method. Am J Clin Pathol. 1966;45:493-496. doi: 10.1093/ ajcp/45.4_ts.493

7. Clinical and Laboratory Standards Institute (CLSI).Performance standards for antimicrobial susceptibility testing. $17^{\text {th }}$ informational supplement: 2007:M100-S17.

8. Trampuz A, Zimmerli W. Diagnosis and treatment of infections associated with fracture-fixation devices. Injury. 2006;37(Supp| 2):S59-66. doi: 10.1016/j. injury.2006.04.010

9. Nichols RL. Preventing surgical site infections: a surgeon's perspective. Emerg Inf Dis. 2001;7(2):220224. doi: 10.3201/eid0702.010214

10. Koyagura B, Koramutla HK, Ravindran B, Kandati J. Surgical site infections in orthopaedic surgeries: incidence and risk factors at tertiary care hospital of South India. Int J Res Orthop. 2018;4(4):551-555. doi: 10.18203/issn.2455-4510.IntJResOrthop20182598

11. Yang J, Zhang $X$, Liang W. A retrospective analysis of factors affecting surgical site infection in orthopaedic patients. J Int Med Res. 2020;48(4):1-9. doi: 10.1177/0300060520907776

12. Kumar S, Sengupta M, Hada V, Sarkar S, Bhatta R, Gupta MS. Early post-operative wound infection in patients undergoing orthopedic surgery with implant. Int J Sci Stud. 2017;5(8):44-48.

13. Maksimovic J, markovic-Denic L, Bumbasirevic $M$, Marinkovic J, Vlajinac H. Surgical Site Infections in Orthopedic Patients: Prospective Cohort Study. Croat Med J. 2008;49(1):58-65. doi: 10.3325/cmj.2008.1.58

14. Amare B, Abdurrahman Z, Moges B, Ali J. Postoperative surgical site bacterial infections and drug susceptibility patterns at Gondar University Teaching Hospital, Northwest Ethiopia. J Bacteriol Parasitol. 2011;2(8). doi: 10.4172/2155-9597.1000126

15. Negi V, Pal S, Juyal D, Sharma MK, Sharma N. Bacteriological Profile of Surgical Site Infections and Their Antibiogram: A Study From Resource Constrained Rural Setting of Uttarakhand State, India. J Clin Diagn Res. 2015;9(10):DC17-DC20. doi: 10.7860/ JCDR/2015/15342.6698

16. Roel T, Devi S, Devi M, Sahu B. Susceptibility pattern of aerobic bacterial isolates from wound swab. Indian Med Gaz. 2014;148(10):355-359.

17. Devi PV, Reddy PS, Shabnum M. Microbial profile and antibiotic susceptibility pattern of orthopedic infections in a tertiary care hospital: A study from South India. Int J Med Sci Public Health. 2017;6(5):838841. doi: 10.5455/ijmsph.2017.1165105122016

18. Benabdelsalem A, Berrady MA, Khermaz M, Mahfoud M, Berrada MS, Elyaacoubi M. Bacteriological profile of surgical site infections in orthopedic surgery about 142 cases. Int J Sci Technol Res. 2014;3(3):271-277.

19. Narula H, Chikara G, Gupta P. A prospective study on bacteriological profile and antibiogram of postoperative wound infections in a tertiary care hospital in Western Rajasthan. J Family Med Prim Care. 2020;9(4):1927-1934. doi: 10.4103/jfmpc. jfmpc_1154_19

20. Das R, Singh A, Srivastava P, Pradhan S, Murthy R. Microbial Profile and Antibiotic Susceptibility Pattern of Surgical Site Infections in Orthopaedic Patients at a Tertiary Hospital in Bilaspur. Int J Sci Stud. 2015;3(3):4347. 